\title{
Study of Functional Outcome in Calcaneal Fractures.
}

\author{
(Dr. Krishna Prasad Nimmagadda ${ }^{1}$, Dr. Saketh Kolla ${ }^{2}$, \\ Dr. Somanadham Vithala ${ }^{3}$ ) \\ 1,2,3 (Dept of Orthopaedics, Dr.PSIMS\&RF, Andhra Pradesh)
}

\begin{abstract}
:
Background: $75 \%$ of calcaneal fractures are intra articular. Treating calcaneal fractures is a challenge for orthopaedic surgeon due to the complex fracture pathology. A wide range of treatment options varying from non operative to operative methods are available. The purpose of this study is to assess the functional outcome of conservatively treated and operatively managed intra articular calcaneal fractures.

Methods: 25 intra articular fractures have been classified as per Computerized Tomography based Sanders system.11 fractures were treated conservatively.11 fractures were treated with open reduction and internal fixation with bone grafting and plating. 3 fractures were treated with percutaneous screw fixation. Functional outcome was assessed using Modified Rowe score after following the cases over mean period of 24 months.

Results: In conservatively managed 11 fractures, average functional outcome score was good in 6 Sanders Type-I fractures, average functional outcome score was satisfactory in 3 Sanders Type -II fractures and was poor in 2 Type-III Sanders fractures. In percutaneously fixed 3 cases of Sanders Type -II intra articular fractures by screws, average functional outcome score was good. In fractures fixed with open reduction and internal fixation with bone grafting and plating, average functional outcome score was excellent in 6 Sanders Type-II fractures and good in 5 Sanders Type-III fractures.

Conclusion: Sanders Type-I fractures can be treated conservatively with good functional outcome. Managing Sanders Type II and III conservatively results in satisfactory to poor outcome. Hence for Sanders Type-II and Type-III, Open reduction and internal fixation with plating and bone grafting has to be considered for achieving excellent functional outcome. Percutaneous screw fixation can also be considered which yields good functional outcome and less post operative complications.
\end{abstract}

Key words: Calcaneum, conservative, plating, screws, Sanders classification, Modified Rowe scale.

\section{Introduction}

Calcaneum fractures account for $2 \%$ of all fractures, $60 \%$ of tarsal bone fractures. $10 \%$ of fractures are bilateral and $75 \%$ are intra articular ${ }^{1} .10 \%$ of fractures are associated with vertebrae fractures. Mechanism of injury in majority of patients is axial loading i.e. fall from height. Other mechanisms are brake pedal injuries and high velocity trauma. Current development in imaging technology has allowed better understanding of this complex fracture pathology. Sanders classification ${ }^{3}$ of intra articular Calcaneum fractures is widely used now a days because of its proven correlation with management and prognosis. Treating Calcaneum fractures is a challenge for orthopaedic surgeon. Treatment options ranges from non operative to operative methods ${ }^{4,13}$. Some studies show advantage to internal fixation whereas some show no difference ${ }^{6,14}$. Hence, a study has been carried out with the aim to assess the functional outcome of conservatively and operatively managed intra articular calcaneal fractures.

\section{Materials And Methods}

There were 25 intra articular fractures in 22 patients in 1 year which were treated. Mean patient age was 35 years. 20 patients were male $(90.9 \%)$ and 2 were females $(9.1 \%)$. Right Calcaneum was involved in 12 cases $(54.5 \%), 7$ cases $(31.8 \%)$ had left Calcaneum fracture, 3 cases $(13.7 \%)$ had bilateral calcaneum fractures. Mechanism of injury was fall from height in all patients. 2 patients $(9.1 \%)$ had associated vertebra fractures without neurological deficit. Patients were evaluated clinically and radiologically, lateral (Fig.2.), axial (Fig.3.) radiographs of Calcaneum were taken. A routine pre operative Computerized Tomography (Fig.4, Fig.5.) was taken. Sanders system ${ }^{3}$ (Table 2) was used for classifying intra articular fractures.11 intra articular fractures $(44 \%)$ which included Sanders type-I, poor local condition, medically unfit patients, peripheral vascular disease and patients who are unwilling for surgery have been treated conservatively with limb elevation and immobilization in plaster for 8 weeks. 14 intra articular fractures $(56 \%)$ were fixed internally under fluoroscopic guidance on an average in 10 days of injury once wrinkle sign is positive. The aim of treatment was to achieve articular surface reconstruction, to restore height, width of axis of heel by performing primary osteosynthesis. In surgically treated fractures, percutaneous screw fixation was done for 3 intra articular fractures $(21.4 \%)$ and open reduction and internal fixation with locking plates and bone grafting was done in 11 
intra articular fractures (79.6\%). Extensile lateral approach (Fig.6.) with ipsilateral iliac crest graft was used to fill the defect after elevating the depressed posterior articular facet in all cases which were internally fixed with plating (Fig.7.). Axial and Broden views were assessed under fluoroscopy intra operatively. Satisfactory reduction was achieved in all cases . For comparision of corrected Bohlers and Gissane angles, post operative radiographs were taken (Fig.8.). Post operatively limb elevation was maintained for 72 hours. Compressive bandage was applied over sterile dressing. Complete suture removal was done at an average of 18 days. All operated patients were kept on absolute non weight bearing for 4 weeks followed by touchdown weight bearing with active and passive movements of ankle and sub talar joints. Full weight bearing was allowed from 12 weeks. Regular clinical follow up examination was performed monthly in all cases and functional outcome was assessed by using Modified Rowe scale (Table 3) after following the cases over a mean period of 24 months.

\section{Case 1:}

\section{Fig.1.Left Ankle(Normal)-Lateral View Fig.2.Pre-op Right Ankle-Lateral view}

Bohlers angle: $28^{\circ} \mathrm{Gissane}$ angle: $113^{\circ}$ Bohlers angle: $18^{\circ}$ Gissane angle: $143^{\circ}$ Fig.3.Right axial view
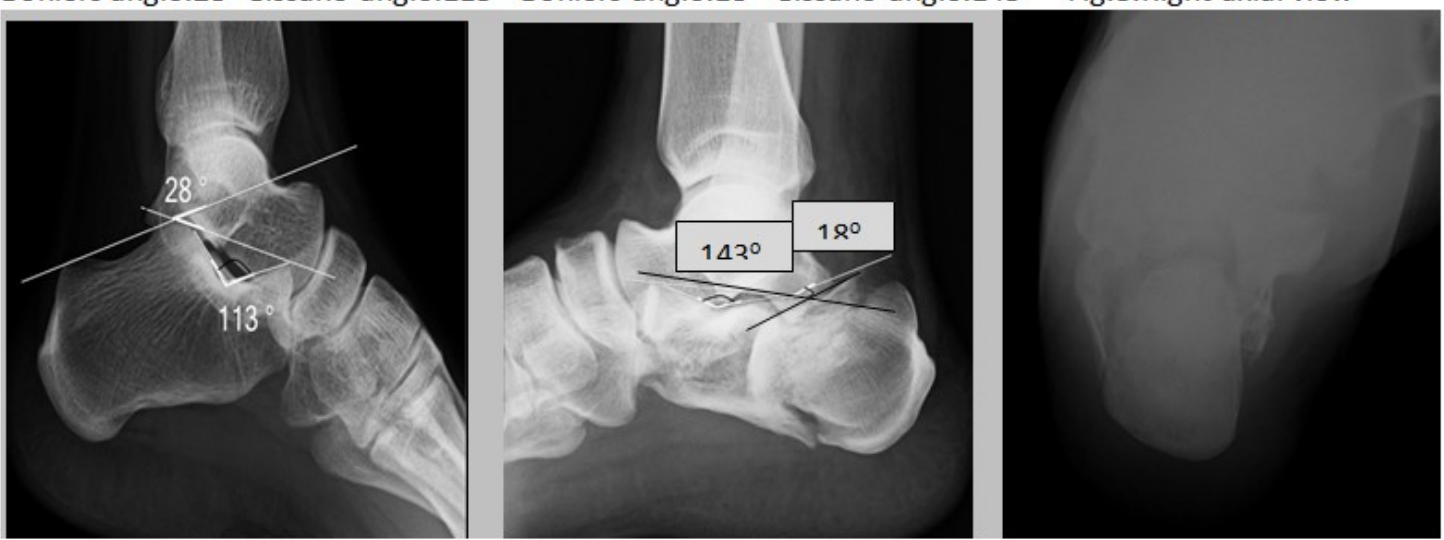

Fig.4, 5.Pre-op Computerized Tomography (Reconstructive images)
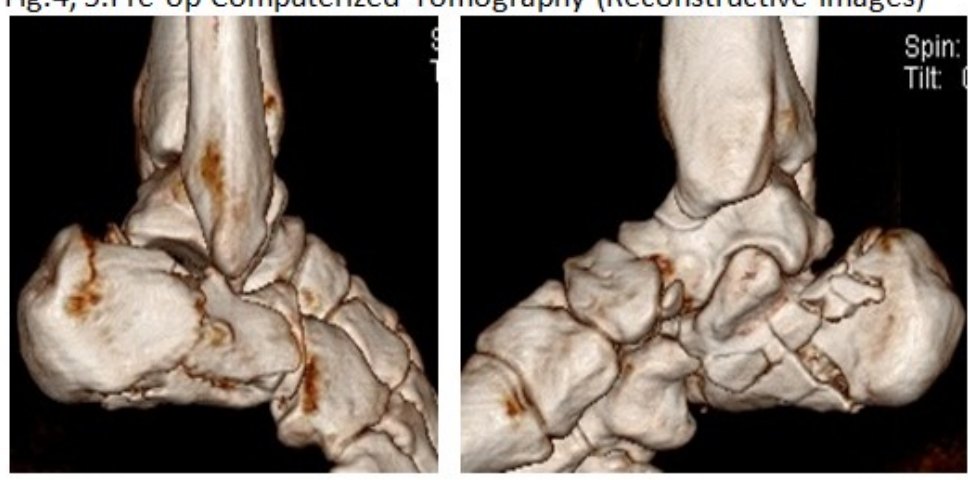

Fig.6. Extensile lateral approach

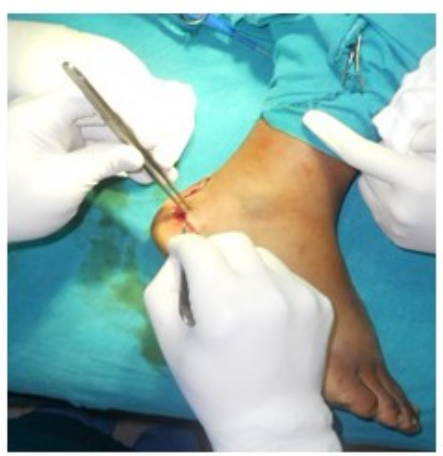

Fig.7.Intra-operative:

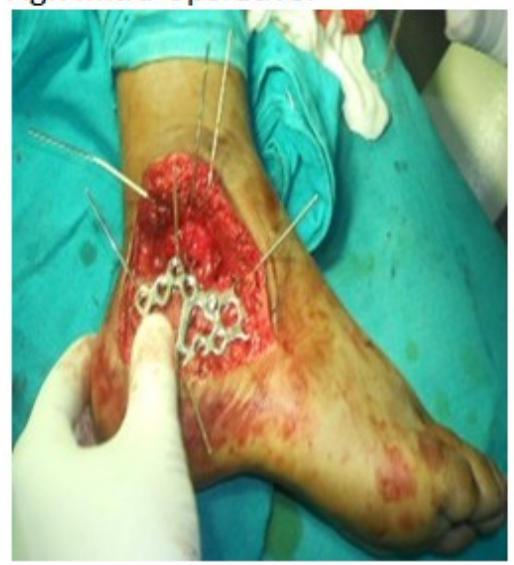

Fig.8.Post-op Right ankle Lateral view

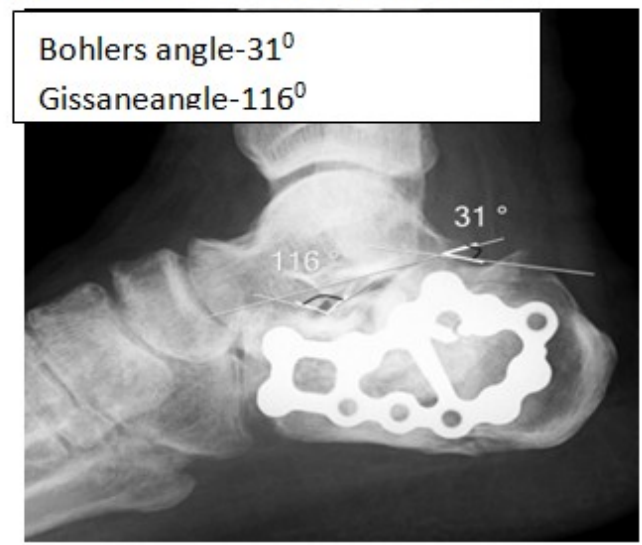


Fig.9.Post op Right Axial view

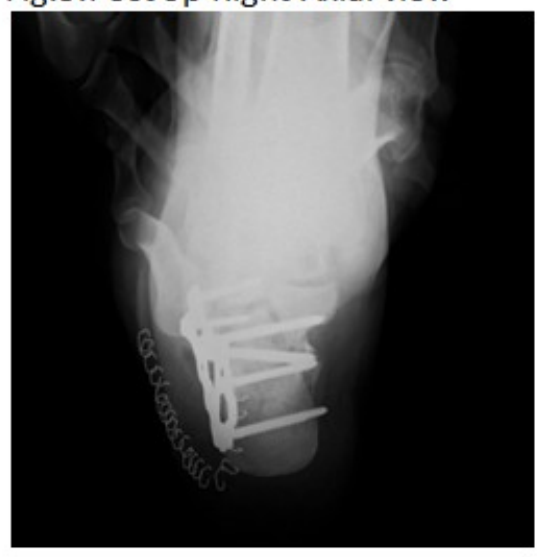

Case 2 :

Pre-op left ankle-lateral view Bohlers angle: $15^{\circ}$ Gissane angle: $142^{0}$

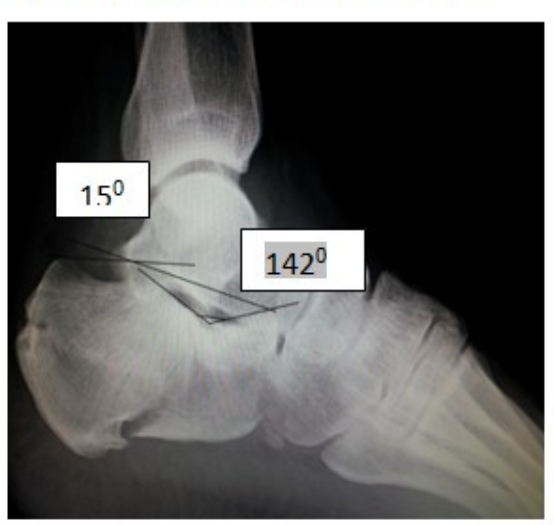

Extensile lateral approach

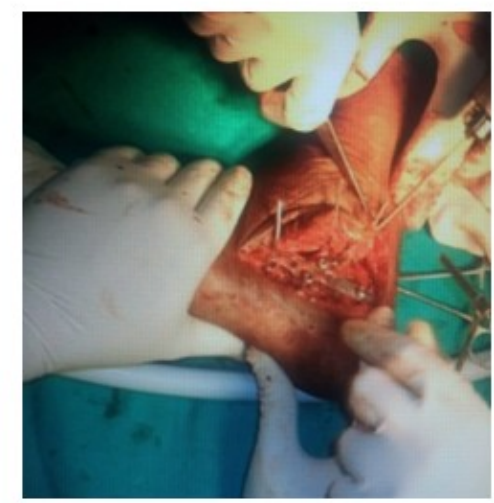

Fig.10.Surgical scar:

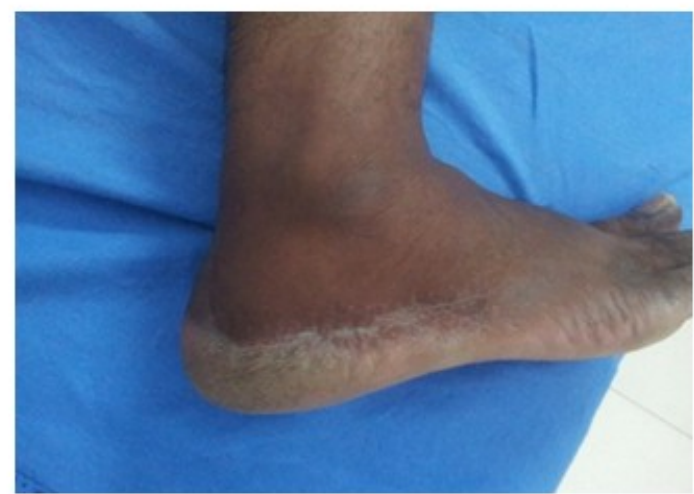

Pre-op left axial view:

Computerised Tomography (Reconstructive Image)
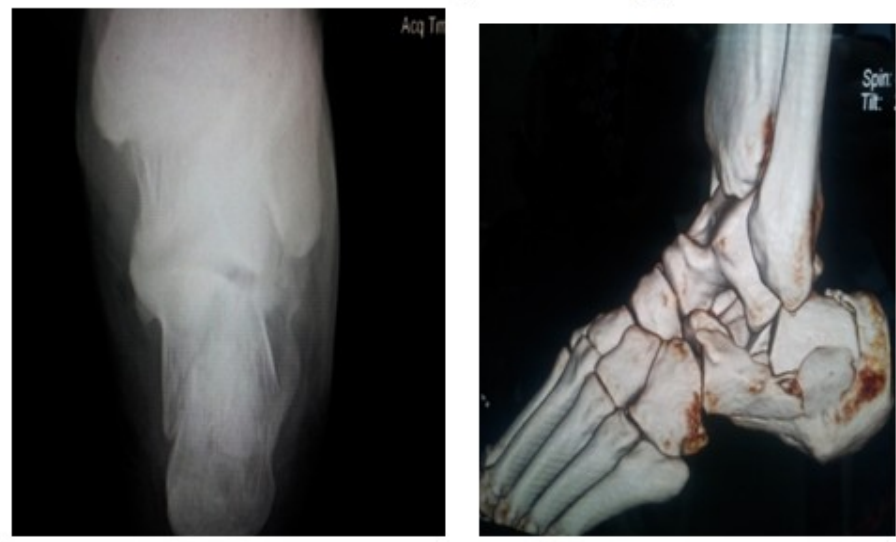

Post-op Left ankle-lateral view: Post op Left Axial View Bohlers angle: $22^{\circ}$ Gissane angle: $120^{\circ}$
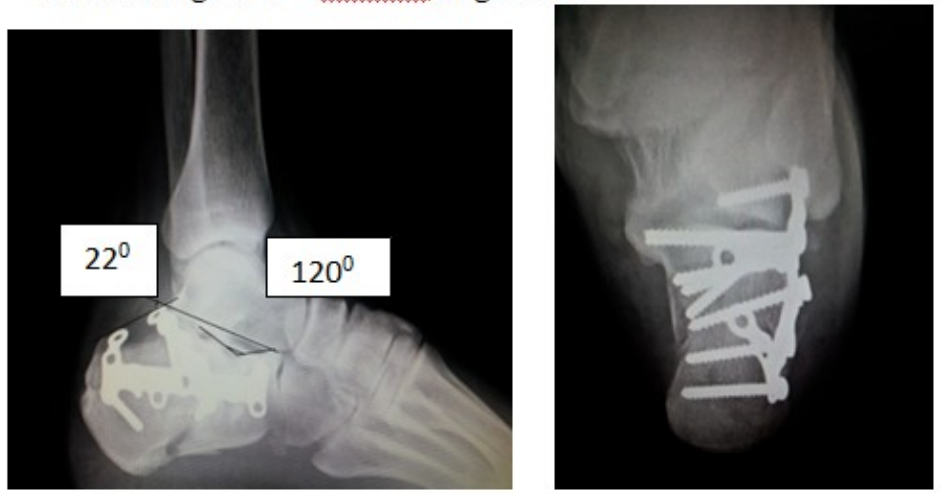
Case 3:

Pre op Left Ankle-A.P View

Gissane angle: $140^{\circ}$ Bohlers angle: $16^{0}$

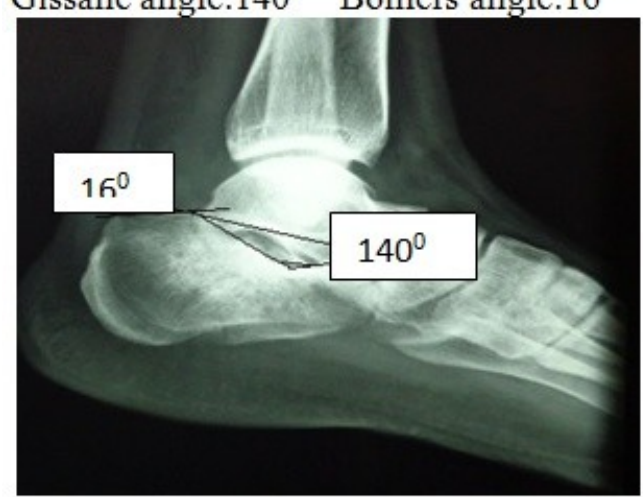

Extensile lateral approach:

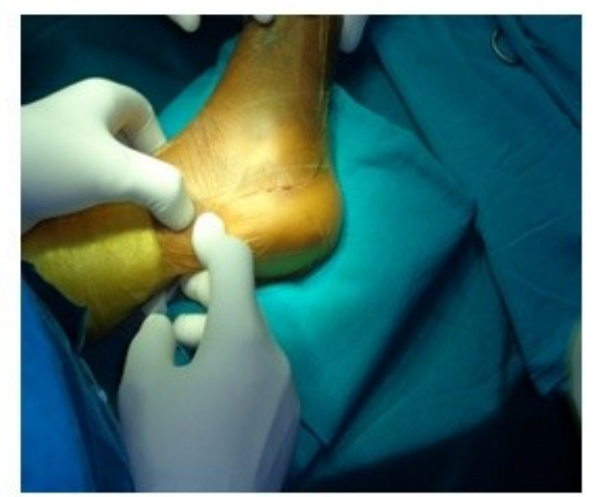

Intra operative images:
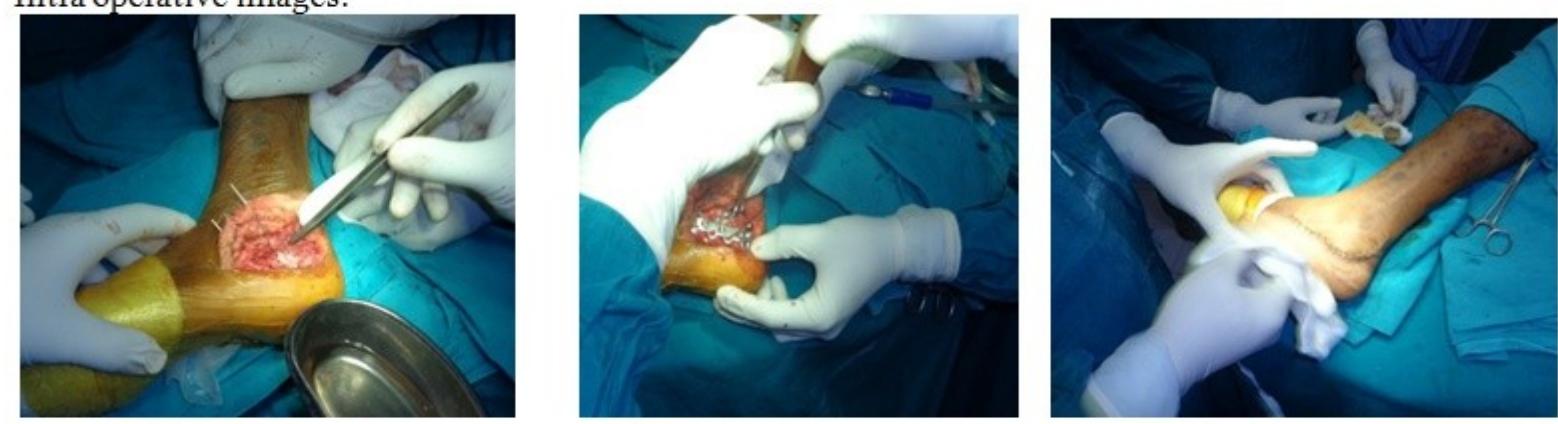

Post op left ankle-lateral view

Gissane angle: $110^{\circ}$, Bohlers angle: $24^{\circ}$

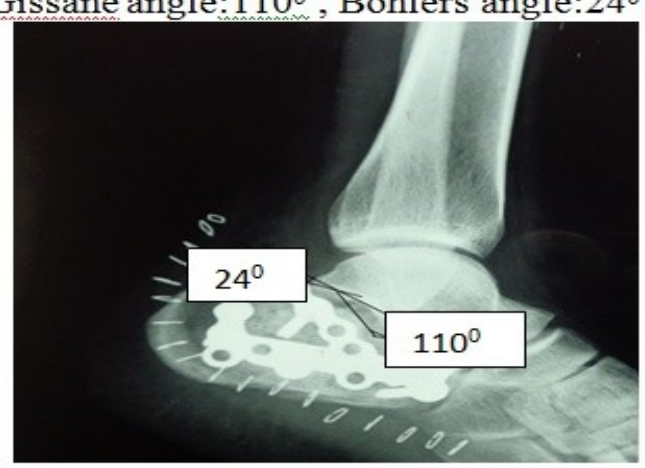

Post op Left Axial view:

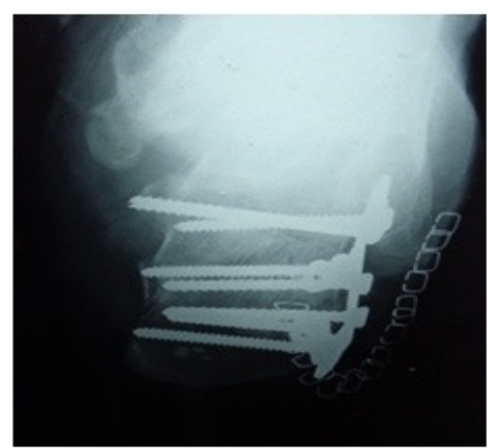

Case 4:

Calcaneum fracture treated with percutaneous cc screw fixation: Pre op left ankle-lateral view:

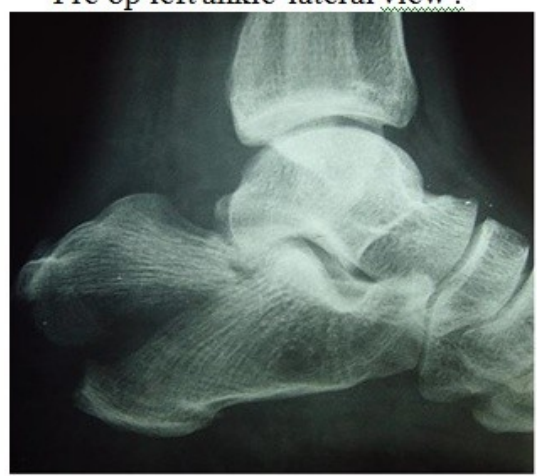
Post op left ankle-lateral view:

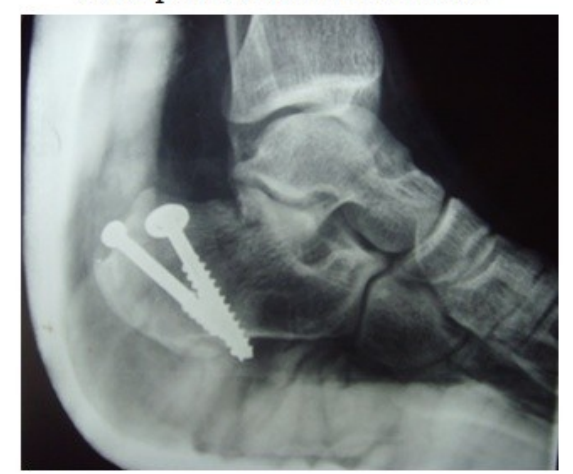




\section{Results}

There were 25 intra articular fractures in 22 patients in 1 year which were treated. 11 intra articular fractures (44\%) were treated conservatively. 14 intra articular fractures (56\%) were surgically managed. Percutaneous screw fixation was done for 3 intra articular fractures $(21.4 \%)$ and open reduction and internal fixation with locking plates with bone grafting was done in 11 intra articular fractures (79.6\%). Mean patient age was 35 years. 20 patients were male $(90.9 \%)$ and 2 were females $(9.1 \%)$. Right Calcaneum was involved in 12 cases $(54.5 \%), 7$ cases $(31.8 \%)$ had left Calcaneum fracture, 3 cases $(13.7 \%)$ had bilateral Calcaneum fractures. As per Sanders classification Type-I fractures were 6(24\%), Type-II were 12(48\%), Type-III were 7(28\%). 6 Sanders type-I fractures (100\%) were treated conservatively. Out of 12 Sanders Type-II fractures $3(25 \%)$ were treated conservatively, $3(25 \%)$ with percutaneous screw fixation, $6(50 \%)$ with open reduction and internal fixation with plating and bone grafting. Out of 7 Sanders type-III fractures, 2(28.6\%) were treated conservatively and remaining 5(71.4\%) were operated with open reduction and internal fixation with plating and bone grafting. Pre-operatively Bohlers angle was decreased to average of 15 degrees. Post operatively Bohlers angle was restored to average of 30 degrees. Post operative average Gissane angle was 110 degrees.

Patients Distribution as per functional outcome as per Modified Rowe $\operatorname{score}^{14}$ :

Table 1:

\begin{tabular}{|c|c|c|c|c|c|c|c|}
\hline & & \multicolumn{2}{|c|}{ Conservative Management } & \multicolumn{2}{|c|}{$\begin{array}{l}\text { Operative Management } \\
\text { (percutaneous screw } \\
\text { fixation) }\end{array}$} & \multicolumn{2}{|c|}{$\begin{array}{l}\text { Operative Management } \\
\text { (ORIF with plating and bone } \\
\text { grafting) }\end{array}$} \\
\hline & $\begin{array}{l}\text { Total No. of } \\
\text { patients }\end{array}$ & \multicolumn{2}{|l|}{11} & \multicolumn{2}{|l|}{3} & \multicolumn{2}{|c|}{11} \\
\hline $\begin{array}{l}\text { Sanders } \\
\text { Type }^{3}\end{array}$ & $\begin{array}{l}\text { Total No. of } \\
\text { patients }\end{array}$ & $\begin{array}{l}\text { No. of } \\
\text { patients } \\
\text { treated }\end{array}$ & $\begin{array}{l}\text { Average Modified } \\
\text { Rowe Score }\end{array}$ & $\begin{array}{l}\text { No. of } \\
\text { patients } \\
\text { treated }\end{array}$ & $\begin{array}{l}\text { Average } \\
\text { Modified } \\
\text { Rowe } \\
\text { Score }^{14}\end{array}$ & $\begin{array}{l}\text { No. of } \\
\text { patients } \\
\text { treated }\end{array}$ & $\begin{array}{l}\text { Average Modified } \\
\text { Rowe Score }\end{array}$ \\
\hline II & 12 & 3 & 60(Satisfactory) & 3 & 75 (Good) & 6 & 86.6(Excellent) \\
\hline III & 7 & 2 & 50 (Poor) & \multicolumn{2}{|l|}{ Nil } & 5 & 80 (Good) \\
\hline IV & Nil & \multicolumn{2}{|c|}{ Nil } & Nil & & \multicolumn{2}{|c|}{ Nil } \\
\hline
\end{tabular}

$\begin{array}{ll}\text { Modified Rowe } & \text { score } \\ \text { Excellent } & >85 \\ \text { Good } & 70-85 \\ \text { Satisfactory } & 55-70 \\ \text { Poor } & <55\end{array}$

In conservatively managed 11 fractures-average functional outcome score was good in 6 Sanders Type-I fractures, average functional outcome score was satisfactory in 3 Sanders Type -II fractures and was poor in 2 Type-III Sanders fractures. In percutaneously fixed 3 Sanders Type -II intra articular fractures by screws, average functional outcome score was good. Average functional outcome score was excellent in 6 Sanders Type-II fractures and good in 5 Sanders Type-III fractures fixed with open reduction and internal fixation with bone grafting and plating.

In patients treated with open reduction and internal fixation with plating and bone grafting wound dehiscence was seen in 1 patient $(9.1 \%)$ which was healed with clean compressive dressings. No other complications were observed.

\section{Discussion}

Intra-articular fractures account for approximately $75 \%$ of calcaneal fractures ${ }^{1}$, and are commonly associated with other axial load injuries giving rise to lumbar vertebral fractures. Mechanism of injury of the Calcaneum fracture causes a major soft tissue injury that includes heel pad, skin and other soft tissues. Lateral, axial and Broden view radiographs are used to examine calcaneal fractures. CT diagnostic provided improved understanding of calcaneal fractures and led to a clinically relevant classification of these injuries 3,4 . CT scans give additional information ${ }^{3,4}$ on (1) the size and number of fracture fragments, (2) the size and displacement of sustentacular tali relative to superior medial fragments, (3) the presence of a step or diastasis of the posterior facet, and (4) impingement of the fibular malleolus on the tuberosity of the Calcaneum. Such scans also provide information regarding fractures involving the sinus tarsi, calcaneocuboid joint, and anterior calcaneal process, all of which could be relevant while planning the lateral surgical approach. Thus a better surgical planning became possible. CT evaluation of calcaneal fractures has allowed classification systems to offer prognostic significance. 
Sanders classification ${ }^{3}$ based on C.T was used in our study (Table 2).

Table 2:

\begin{tabular}{|l|l|}
\hline $\begin{array}{l}\text { Sanders } \\
\text { Type }^{3}\end{array}$ & Description \\
\hline I & $\begin{array}{c}\text { Non-displaced fracture irrespective of the number } \\
\text { of fracture lines }\end{array}$ \\
\hline II & Two parts fragment or split fracture \\
\hline III & Three parts fracture or split depression \\
\hline IV & Four parts fracture or highly comminuted \\
\hline
\end{tabular}

\section{Sanders classification:}

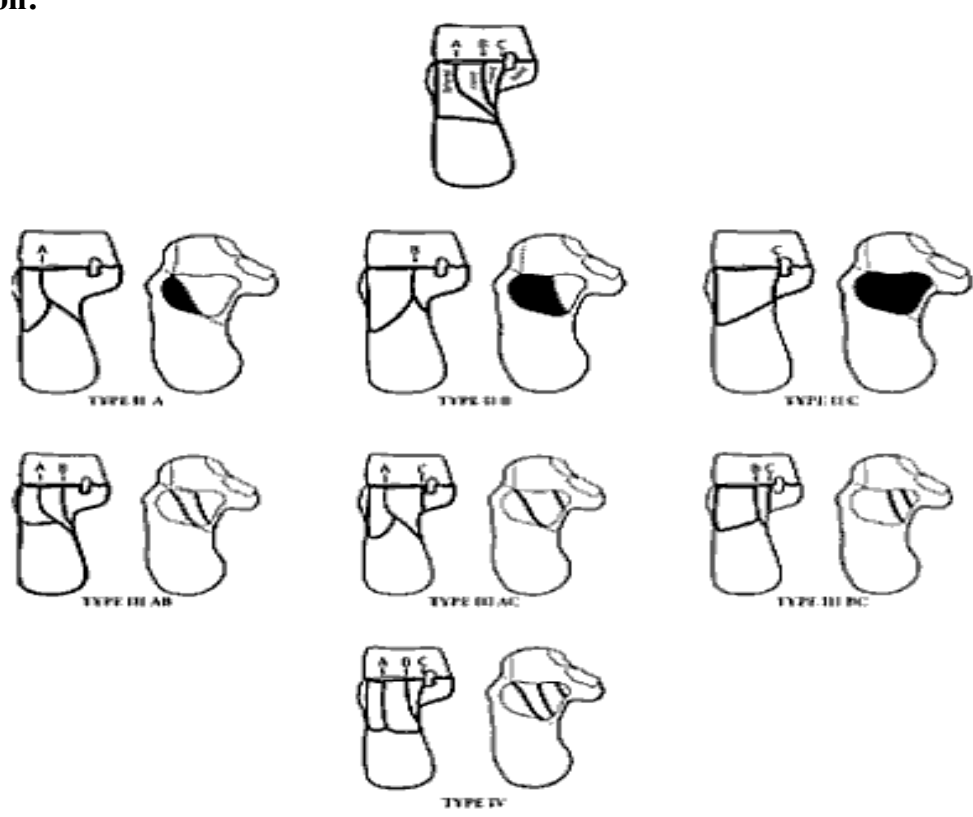

The treatment goals ${ }^{2,5}$ are: (1) restoration of congruency of the posterior facet of subtalar joint,(2) restoration of the calcaneal height and width,(3) decompression of the sub fibular space available for the peroneal tendons, (4) realignment of the tuberosity in a valgus position, and (5) reduction of the calcaneocuboid joint.3) small subtalar incongruity of only $1 \mathrm{~mm}$ can lead to early arthritis of the corresponding joints . Conservative treatment ${ }^{9}, 10$ is sufficient in Sanders Type I fractures which results in good functional outcome. Operative methods of treatment 2, 11, 12 have included attempts at closed reduction or percutaneous manipulation, percutaneous screw fixation, open reduction with internal fixation, bone grafting or both, and primary arthrodesis of the subtalar joint. To correct calcaneal anatomy, open reduction should be advised to patients. Open reduction and internal fixation $8,15,20$ is now more aggressively advocated for management of displaced Sanders type II or III calcaneal intra articular fractures to achieve anatomical reduction, to decrease the complication of subtalar arthritis and joint incongruity.. Because of the risk of early complications, the timing of surgery i.e. after local swelling subsides is of principal importance. We used the lateral extensile approach ${ }^{15}$ because it provides wide exposure of the subtalar joint and allows more accurate exposure of the facet fragments and calcaneocuboid joint, easier decompression of the lateral wall, and sufficient area laterally for plate fixation. Bone grafting ${ }^{16}$ is essential to prevent collapse and maintain the height of Calcaneum and to add mechanical support and to probably stimulate earlier fracture healing.

As lateral wall is subcutaneous, any implants on the surfaces can lead to early post-operative complications like wound dehiscence, necrosis of wound edges, and early superficial infection. Use of percutaneously screw fixation ${ }^{18}$ with minimum soft tissue dissection can be opted which also results in less post operative swelling and considerably yields good functional outcome ${ }^{17,19}$. The functional outcome in our study was assessed by using Modified Rowe scale ${ }^{14}$ (Table 3). 


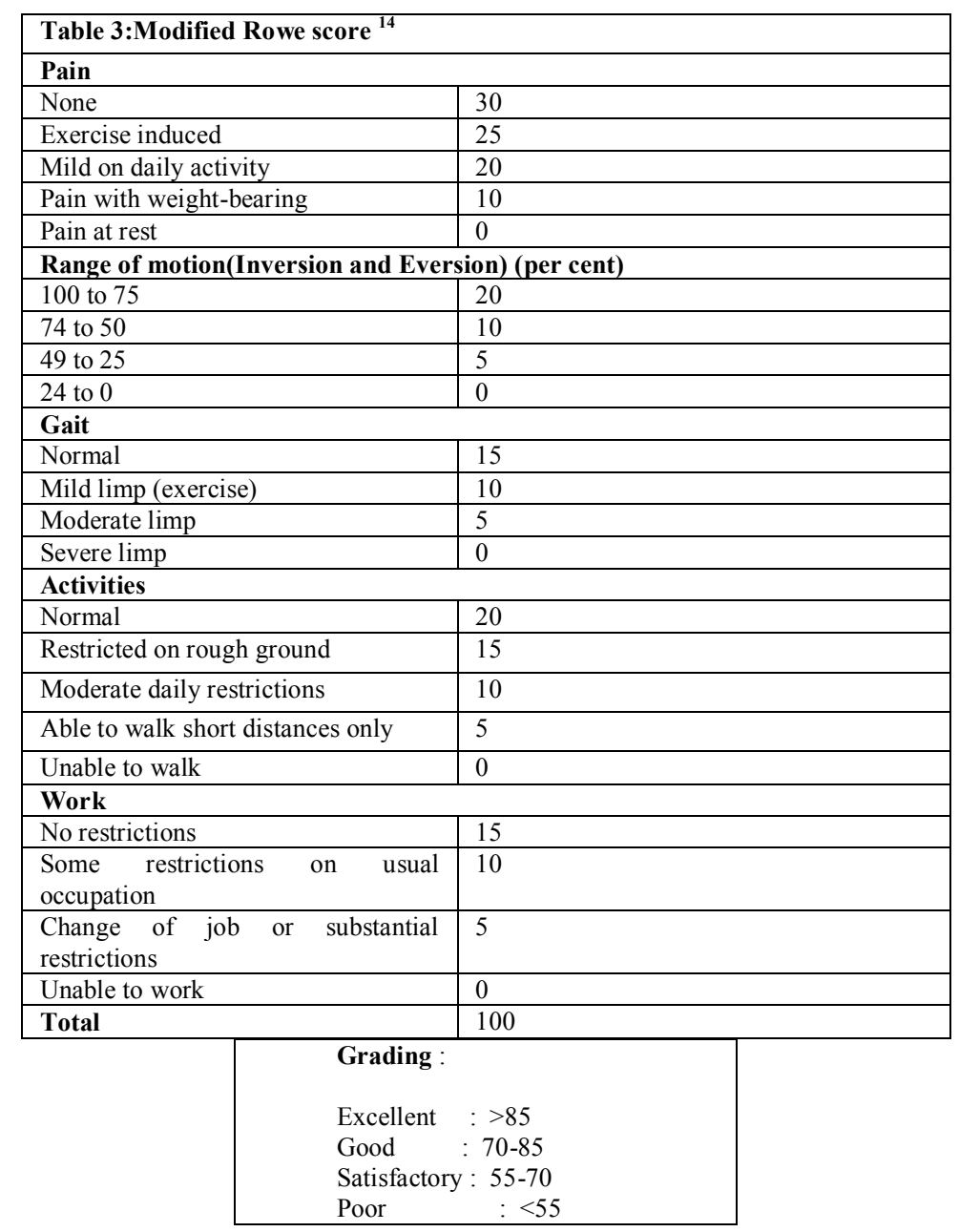

Our study showed that in conservatively managed fractures, average functional outcome score was good in Sanders Type-I fractures, satisfactory in Sanders Type -II fractures and was poor in Type-III Sanders fractures. In percutaneously fixed Sanders Type-II intra articular fractures by screws, average functional outcome score was good. In fractures fixed with open reduction and internal fixation with bone grafting and plating, average functional outcome score was excellent in Sanders Type-II fractures and good in Sanders Type-III fractures.

\section{Conclusion}

Sanders Type-I fractures can be treated conservatively with good functional outcome. Managing Sanders Type II and III conservatively results in satisfactory to poor outcome. Hence for Sanders Type-II and Type-III, Open reduction and internal fixation with plating and bone grafting has to be considered for achieving excellent functional outcome. Percutaneous screw fixation can also be considered which yields good functional outcome and less post operative complications.

\section{Conflict of interest:}

The authors declare that they haven't any conflict of interest.

\section{References}

[1]. Fitzgibbons TC, McMullen ST, Mormino MA. Fractures and dislocations of the calcaneum. In: Bucholz RW and Heckman JD Eds. Rockwood and Green's Factures in adults, Vol.3, 5th ed. Philadelphia: Lippincott Williams \& Wilkins, 2001: 2133-2179.

[2]. Leung KS, Yuen KM, Chan WS. Operative treatment of displaced intra-articular fractures of the Calcaneum. J Bone Joint Surg (Br). 1993; 75:196-201

[3]. Sanders R, Fortin P, Diapasquale T, Walling A. Operative treatment in 120 displaced calcaneal fractures: results using a prognostic computed tomography scan classification. Clin Orthop. 1993; 290:295

[4]. Sanders R. Intra-articular fractures of the calcaneum: present state of the art. J Orthop Trauma. 1996; 6:252-265.

[5]. Crosby LA, Fitzgibbons TC. Open reduction and internal fixation of type II intra-articular calcaneum fractures. Foot Ankle Int. $1996 ; 17: 253-258$

[6]. Jarvholm U, Korner L, Thoren O, Wiklund LM. Fractures of the calcaneum: a comparison of open and closed treatment. Acta Orthop Scand 1984; 55:652-6 
[7]. Pozo JL, Kirwan EOG, Jackson AM. The long-term results of conservative management of severely displaced fractures of the Calcaneum. J Bone Joint Surg. [Br] 1984; 66-B:386-90

[8]. Huang PJ, Huang HT, Chen TB. Open reduction and internal fixation of displaced intra-articular fractures of the Calcaneum. J Trauma. 2002;52946-951

[9]. Kitaoka HB, Schaap EJ, Chao EY, An KN. Displaced intra-articular fractures of the Calcaneum treated non- operatively. Clinical results and analysis of motion and ground-reaction and temporal forces. J Bone Joint Surg Am 1994; 76:1531-40.

[10]. Thordarson DB, Krieger LE. Operative vs. nonperative treatment of intra-articular fractures of the Calcaneum: a prospective randomized trial. Foot Ankle Int 1996; 17:2-9.

[11]. Chan S, Ip FK. Open reduction and internal fixation for displaced intra-articular fractures of the os calcis. Injury 1995;26:111-5.

[12]. Hutchinson F 3rd, Huebner MK. Treatment of os calcis fractures by open reduction and internal fixation. Foot Ankle Int 1994; 15:225-32.

[13]. Eastwood DM, Phipp L. Intra-articular fractures of the Calcaneum: why such controversy? Injury1997;28:247-59.

[14]. Buckley RE, Meek RN. Comparison of open versus closed reduction of Intraarticular calcaneal fractures: a matched cohort in workmen. J Orthop Trauma. 1992;6:216-22.

[15]. Zeman P, Zeman J, Matejka J, Koudela K. Long-term results of calcaneal fracture treatment by open reduction and internal fixation using a calcaneal locking compression plate from an extended lateral approach. Acta Chir Orthop Traumatol Cech. 2008 Dec; 75(6):457-64.

[16]. Leung KS, Chan WS, Shen WY, Pak PPL, So W-S, Leung PC. Operative treatment of Intraarticular fracture of the os calcis; the role of rigid internal fixation and primary bone grafting : preliminary results. J Orthop Trauma. 1989; 3:232

[17]. Kevin A et al. Functional outcome measures after displaced intra-articular calcaneal fractures. J Bone Joint Surg Br. 1996; 78-B: 119- 23.

[18]. Levine DS, Helfet DL. An introduction to the minimally invasive osteosynthesis of intra-articular calcaneal fractures. Injury. 2001 May; 32 Suppl 1:SA51-4.

[19]. Potter MQ, Nunley JA.Long-term functional outcomes after operative treatment for intra-articular fractures of the Calcaneum. J Bone Joint Surg Am. 2009 Aug; 91(8):1854-60. doi: 10.2106/ JBJS.H.01475.

[20]. O'Farrell DA, O’Byrne JM, McCabe J, Stephens MM. Fractures of the os calcis: improved results with internal fixation. Injury 1993; $24: 263-5$. 